\title{
Formation of Amorphous Pt Oxides: Characterization and Their Catalysis
}

\author{
Satoshi Kameoka ${ }^{1, *}$, Masahiko Shimoda ${ }^{2}$, Yoshitaka Matsushita ${ }^{2,3}$, Yoshiyuki Yamashita ${ }^{2,3}$, \\ Yoshio Katsuya ${ }^{3}$, Masahiko Tanaka ${ }^{3}$ and An-Pang Tsai ${ }^{1,2}$ \\ ${ }_{1}^{1}$ Institute of Multidisciplinary Research for Advanced Materials (IMRAM), Tohoku University, Sendai 980-8577, Japan \\ ${ }^{2}$ National Institute of Materials Science (NIMS), Tsukuba 305-0047, Japan \\ ${ }^{3}$ Synchrotron X-ray Station at SPring-8, NIMS, Sayo, Hyogo 679-5148, Japan
}

Amorphous Pt oxides $\left(\mathrm{am}-\mathrm{PtO}_{x}\right)$ were formed by the leaching of copper from a $\mathrm{Cu}_{3} \mathrm{Pt}$ alloy in concentrated $\mathrm{HNO}_{3}$ at $323 \mathrm{~K}$ for $12 \mathrm{~h}$. The resulting am- $\mathrm{PtO}_{x}$ was characterized using synchrotron X-ray powder diffraction, hard X-ray photoelectron spectroscopy, thermal analysis (TGDTA, TPD) and the BET method. This material had a high specific surface area with micropores $\left(61.7 \mathrm{~m}^{2} / \mathrm{g}\right)$ and decomposed to form $\mathrm{Pt}$ and $\mathrm{O}_{2}$ at approximately $720 \mathrm{~K}$. The catalytic performance of the $\mathrm{am}-\mathrm{PtO}_{x}$ during $\mathrm{CO}$ oxidation was superior to that of a conventional Pt black catalyst. This study demonstrated a novel method of preparing am- $\mathrm{PtO}_{x}$ with applications as a catalyst. [doi:10.2320/matertrans.MF201410]

(Received January 6, 2015; Accepted January 28, 2015; Published March 6, 2015)

Keywords: amorphous platinum (Pt) oxides, PtO $\mathrm{x}_{x}$ catalytic material, leaching, $\mathrm{Cu}_{3} \mathrm{Pt}$, carbon monoxide (CO) oxidation

\section{Introduction}

Recently, a leaching process using the selective dissolution of the less-noble metal from an alloy in bulk form has been used to fabricate nano- or mesoporous metals with high specific surface areas $\left(\sim 10 \mathrm{~m}^{2} / \mathrm{g}\right)$ as well as unique structural characteristics. ${ }^{1)}$ This leaching technique can generate nanoporous metals with extraordinary structural characteristics. Interestingly, Zielasek et $a .^{2)}$ and $\mathrm{Xu}$ et $a{ }^{2}{ }^{3)}$ reported that the nanoporous gold obtained by leaching silver from $\mathrm{Au}-\mathrm{Ag}$ solid solutions exhibits an unexpectedly high catalytic activity for $\mathrm{CO}$ oxidation even under ambient conditions. Independent of the Au-Ag system, leaching from intermetallic compounds (IMCs) such as $\mathrm{Cu}_{3} \mathrm{Au}$ and $\mathrm{Al}_{2} \mathrm{Au}$ was found to produce homogeneous mesoporous $\mathrm{Au} .{ }^{4,5)} \mathrm{IMCs}$, in which atoms are located at defined positions in an orderly manner, generally have specific stoichiometric compositions. This characteristic ensures homogeneity on the atomic level, as opposed to solid solutions wherein atoms are located randomly at lattice points. In spite of its relatively low specific surface area $\left(\sim 1 \mathrm{~m}^{2} / \mathrm{g}\right)$ mesoporous $\mathrm{Au}$ has exhibited high activity for $\mathrm{CO}$ oxidation, comparable to that of the standard catalyst $\mathrm{Au} / \mathrm{TiO}_{2}{ }^{4}{ }^{4}$ This result implies that the combination of nano-sized $\mathrm{Au}$ and oxide supports in standard catalysts may not be the only means of achieving high activity, and suggests that mesoporous $\mathrm{Au}$ has the potential to act on its own as an unsupported catalyst.

In order to fabricate novel catalytic materials with unique structural characteristics, we have investigated the leaching of a diverse range of binary alloys, including Au-TM and Pt-TM ( $\mathrm{TM}=\mathrm{Fe}, \mathrm{Co}, \mathrm{Ni}, \mathrm{Cu}$ and others). During the course of this study, an amorphous $\mathrm{Pt}$ oxide $\left(\mathrm{am}-\mathrm{PtO}_{x}\right)$ phase was obtained by selective leaching of copper from a $\mathrm{Cu}_{3} \mathrm{Pt}$ alloy using concentrated nitric acid at $323 \mathrm{~K}$. We report herein the characterization of this $\mathrm{am}-\mathrm{PtO}_{x}$ using synchrotron X-ray powder diffraction (SXRD), hard X-ray photoelectron spectroscopy (HXPS), thermal analysis (thermogravimetry-differential thermal analysis: TG-DTA, temperature-programmed decomposition: TPD) and the Brunauer-Emmet-Teller (BET)

*Corresponding author, E-mail: kameoka@tagen.tohoku.ac.jp
Table 1 Results of composition of $\mathrm{Pt}(\mathrm{at} \%)$ and $\mathrm{Cu}(\mathrm{at} \%)$ in $\mathrm{Cu}_{3} \mathrm{Pt}$ sample before and after leaching and surface areas.

\begin{tabular}{ccccc}
\hline \multirow{2}{*}{ Sample } & \multicolumn{2}{c}{ ICP analysis } & Dessolved & \\
\cline { 2 - 3 } & $\mathrm{Pt}(\mathrm{at} \%)$ & $\mathrm{Cu}(\mathrm{at} \%)$ & $\begin{array}{c}S_{\mathrm{BET}} \\
\left(\mathrm{m}^{2} \mathrm{~g}^{-1} \text {-cat }\right)\end{array}$ \\
\hline $\mathrm{Cu}_{3} \mathrm{Pt}-\mathrm{BL}^{* 1}$ & 25.0 & 75.0 & - & $<0.1$ \\
$\mathrm{Cu}_{3} \mathrm{Pt}_{-\mathrm{AL}}{ }^{* 1}$ & 85.4 & 14.6 & 94.3 & $61.7(14.3)^{* 5}$ \\
Pt black $^{* 2}$ & 100 & - & - & $29.0(2.2)^{* 5}$ \\
\hline
\end{tabular}

${ }^{* 1} \mathrm{BL}$ and $\mathrm{AL}$ mean before leaching and after leaching, respectively.

*2 Provided by Wako Chemical Co.

${ }^{* 3}$ Elemental composition of whole sample analyzed by ICP.

${ }^{* 4}$ Amount of extracted $\mathrm{Cu}(\%)$ from original $\mathrm{Cu}_{3} \mathrm{Pt}$.

${ }^{* 5}$ BET surface area $\left(S_{\mathrm{BET}}\right)$ after CO oxidation.

method. The catalytic properties of the $\mathrm{am}-\mathrm{PtO}_{x}$ for $\mathrm{CO}$ oxidation were also investigated and are reported.

\section{Experimental}

$\mathrm{Cu}_{3} \mathrm{Pt}$ alloy was prepared from pure $\mathrm{Pt}$ and $\mathrm{Cu}$ (both $99.9 \%$ pure) in an electric arc furnace under an $\mathrm{Ar}$ atmosphere. A ribbon-shaped sample of the resulting $\mathrm{Cu}_{3} \mathrm{Pt}$ (thickness: ca. $0.02 \mathrm{~mm}$, width: ca. $2.0 \mathrm{~mm}$ ) was fabricated by the single-roller melt spinning method in an Ar atmosphere. This $\mathrm{Cu}_{3} \mathrm{Pt}$ ribbon was subsequently leached in concentrated $\mathrm{HNO}_{3}$ for $12 \mathrm{~h}$ at $323 \mathrm{~K}$, following which the solution was filtered and the remaining solid material was thoroughly washed with distilled water until the filtrate was no longer acidic. The composition (in at\%) of the sample after leaching was determined by inductively couple plasma (ICP) analysis. For comparison, Pt black (Wako 168-11121) was also studied. The sample designations are given in Table 1 . The specific surface areas of samples were determined by BET analysis (BELSORP-mini). SXRD and HXPS analyses were carried out using high brilliance synchrotron radiation generated by NIMS undulator beam line BL15XU $(\lambda=$ $0.065297 \mathrm{~nm}$ for SXRD, hv $=5.951 \mathrm{keV}$ for HXPS) at the SPring-8 facility in Japan. ${ }^{6,7)}$ The morphologies and microstructures of samples were observed using a field-emission scanning electron microscope (SEM, HITACHI S-5500) with an acceleration voltage of $10 \mathrm{kV}$. The TG-DTA and TPD 
measurements were carried out using $50 \mathrm{mg}$ samples heated from room temperature to $1000 \mathrm{~K}$ at a rate of $10 \mathrm{~K} / \mathrm{min}$ under an inert gas flow (Ar or He). The TPD analysis was performed by quadrupole mass spectrometry (QMS, m/e = 32) under the He flow. Reaction trials were performed in a standard fixed-bed flow reactor by passing a gaseous mixture of $\mathrm{CO}(1 \mathrm{vol} \%)$ and $\mathrm{O}_{2}(0.5 \mathrm{vol} \%)$ in He flow at a space velocity (SV) of $20,000 \mathrm{~h}^{-1}$ (total pressure: $1 \mathrm{~atm}$ ). All catalytic experiments were conducted on fresh specimens without any pretreatment. The reaction products were monitored by an on-line gas chromatograph (Shimadzu GC-8A) equipped with a Molecular Sieve 5A (for $\mathrm{O}_{2}$ and $\mathrm{CO}$ ) and a Porapak Q column (for $\mathrm{CO}_{2}$ ). The catalytic activity during the oxidation of $\mathrm{CO}$ with $\mathrm{O}_{2}$ was evaluated by calculating the percentage conversion of $\mathrm{CO}$ to $\mathrm{CO}_{2}$. The data used for the catalytic activity measurements were recorded at the point at which the reaction had reached a steady state after $30 \mathrm{~min}$.

\section{Results and Discussion}

Figure 1 shows the SXRD patterns of the $\mathrm{Cu}_{3} \mathrm{Pt}$ alloy before and after leaching in concentrated $\mathrm{HNO}_{3}$ at $323 \mathrm{~K}$ (hereafter denoted as $\mathrm{Cu}_{3} \mathrm{Pt}-\mathrm{BL}$ and $\mathrm{Cu}_{3} \mathrm{Pt}-\mathrm{AL}$, respectively). All the diffraction peaks present in the BL sample can be attributed to an fcc $\mathrm{Cu}_{3} \mathrm{Pt}$ alloy before leaching $\left(\mathrm{Cu}_{3} \mathrm{Pt}-\mathrm{BL}\right)$, whereas these peaks disappear completely after leaching. Surprisingly, the post leaching sample does not generate any diffraction peaks implying that amorphous phases were formed by the leaching treatment. ICP analysis of the leaching solution determined that only copper ions were present, indicating the selective dissolution of copper from the original $\mathrm{Cu}_{3} \mathrm{Pt}$ alloy. However, some residual copper was also detected in the leached sample by ICP analysis (Table 1), which showed a $\mathrm{Cu}$ content in the $\mathrm{Cu}_{3}$ Pt-AL specimen of 14.6 at $\%$.

Figures 2(A) and 2(B) present SEM micrographs of $\mathrm{Cu}_{3} \mathrm{Pt}-\mathrm{AL}$ obtained with different magnifications, showing a structure consisting of fine nanoparticles. Figure 2(C) presents the isotherm curve obtained during $\mathrm{N}_{2}$ adsorptiondesorption on $\mathrm{Cu}_{3} \mathrm{Pt}-\mathrm{AL}$ at $77 \mathrm{~K}$. This conforms to a type $\mathrm{I}$ plot, typically generated by microporous solids having relatively small external surfaces. ${ }^{8)}$ The BET surface area of

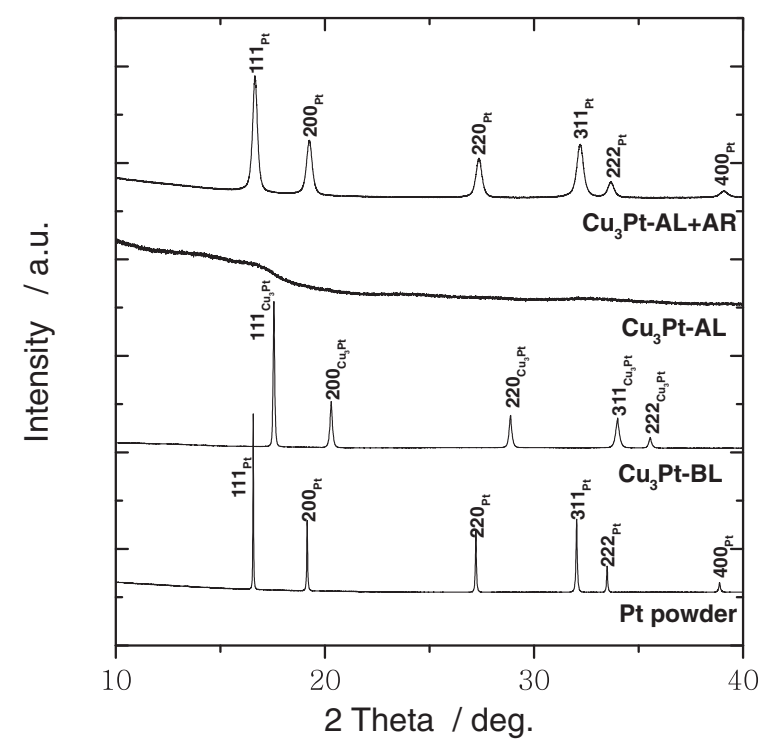

Fig. 1 SXRD patterns of $\mathrm{Cu}_{3} \mathrm{Pt}$ samples before leaching (BL), after leaching (AL) and after $\mathrm{CO}$ oxidation reaction (AL+AR), as well as of $\mathrm{Pt}$ powder, obtained using high brilliance synchrotron radiation (SPring-8 BL15XU, $\lambda=0.065297 \mathrm{~nm}$ ).
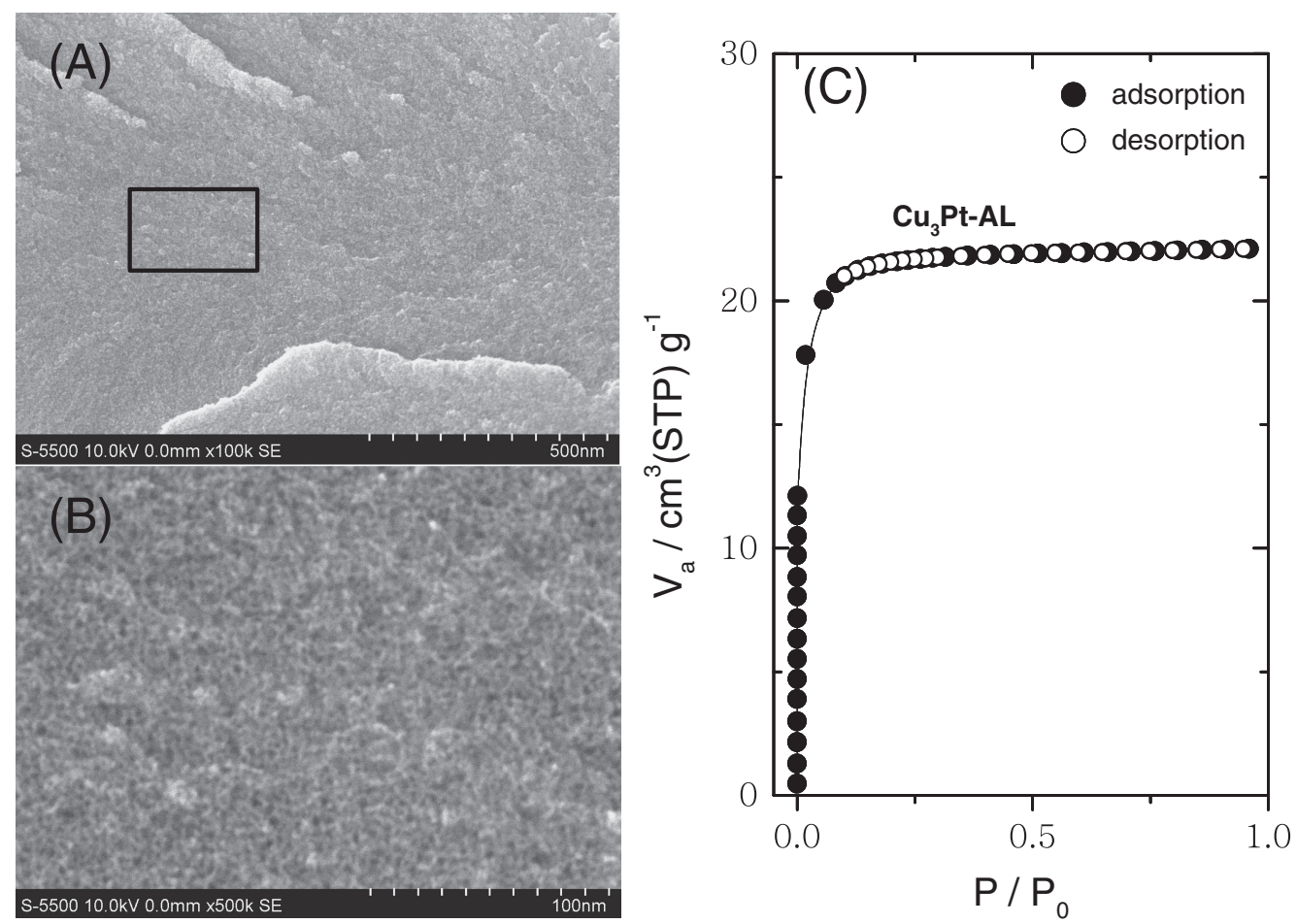

Fig. 2 SEM images of a $\mathrm{Cu}_{3}$ Pt-AL sample under (A) low and (B) high magnification and (C) an isotherm obtained from the $\mathrm{Cu}_{3} \mathrm{Pt}-\mathrm{AL}$ sample. 

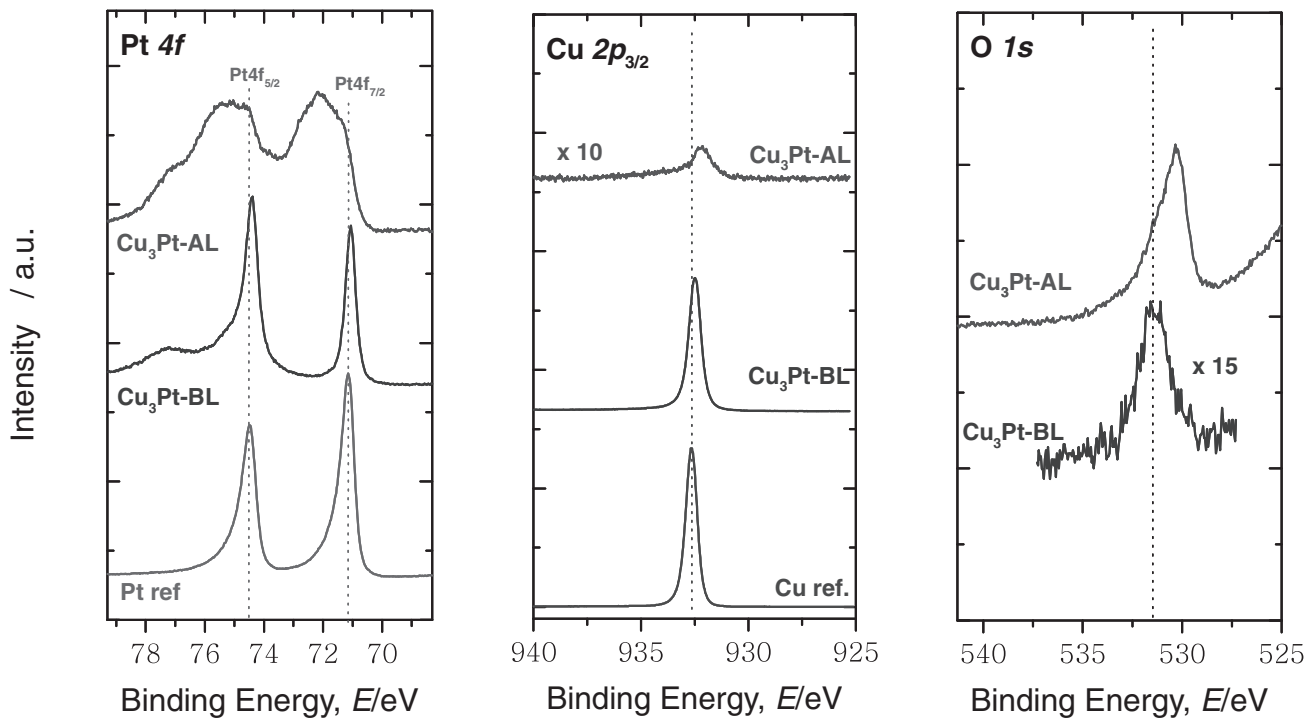

Fig. $3 \mathrm{Pt} 4 f, \mathrm{Cu} 2 p_{3 / 2}$ and $\mathrm{O} 1 s$ HXPS spectra obtained from $\mathrm{Cu}_{3} \mathrm{Pt}-\mathrm{BL}$ and $\mathrm{Cu}_{3} \mathrm{Pt}-\mathrm{AL}$ samples. For comparison, the $\mathrm{Pt} 4 f_{5 / 2}$ and $\mathrm{Pt} 4 f_{7 / 2}$ spectra of $\mathrm{Pt}$ foil and the $\mathrm{Cu} 2 p_{3 / 2}$ spectrum of $\mathrm{Cu}$ foil are also shown.

the $\mathrm{Cu}_{3} \mathrm{Pt}-\mathrm{AL}$ was determined to be $61.7 \mathrm{~m}^{2} / \mathrm{g}$, a value more than three orders larger than that of the original $\mathrm{Cu}_{3} \mathrm{Pt}-\mathrm{BL}$.

Figure 3 shows the $\mathrm{Pt} 4 f, \mathrm{Cu} 2 p_{3 / 2}$ and $\mathrm{O} 1 s$ HXPS spectra obtained from the $\mathrm{Cu}_{3} \mathrm{Pt}-\mathrm{BL}$ and $\mathrm{Cu}_{3} \mathrm{Pt}-\mathrm{AL}$ samples. The Pt $4 f$ photoemission spectrum from $\mathrm{Cu}_{3} \mathrm{Pt}-\mathrm{BL}$ shows sharp peaks at almost the same binding energies (BEs, $4 f_{5 / 2}$ : $\left.74.4 \mathrm{eV}, 4 f_{7 / 2}: 71.1 \mathrm{eV}\right)$ as that from the Pt foil $\left(4 f_{5 / 2}: 74.5 \mathrm{eV}\right.$, $4 f_{7 / 2}: 71.2 \mathrm{eV}$ ), whereas the $\mathrm{Cu}_{3} \mathrm{Pt}-\mathrm{AL}$ reveals a broad spectrum which consists of multiple components located at the same or higher BEs. In the case of the $\mathrm{Cu} 2 p_{3 / 2}$ spectra, although the $\mathrm{BE}$ of $\mathrm{Cu} 2 p_{3 / 2}$ of $\mathrm{Cu}_{3} \mathrm{Pt}-\mathrm{BL}\left(2 p_{3 / 2}: 932.5 \mathrm{eV}\right)$ was almost the same as that of the $\mathrm{Cu}$ foil $\left(2 p_{3 / 2}: 932.6 \mathrm{eV}\right)$, only a very weak $\mathrm{Cu} 2 p_{3 / 2}$ peak was observed for the $\mathrm{Cu}_{3} \mathrm{Pt}$ $\mathrm{AL}\left(2 p_{3 / 2}: 932.2 \mathrm{eV}\right)$. The $\mathrm{O} 1 s$ spectrum of the $\mathrm{Cu}_{3} \mathrm{Pt}-\mathrm{AL}$ exhibits a broad peak at around $530.4 \mathrm{eV}$, while only a trace level peak is seen in the vicinity of $531.4 \mathrm{eV}$ for the $\mathrm{Cu}_{3} \mathrm{Pt}$ $\mathrm{BL}$. Compared to the BEs obtained for the $\mathrm{Cu}_{3} \mathrm{Pt}-\mathrm{BL}$, the Pt $4 f$ peaks of the $\mathrm{Cu}_{3} \mathrm{Pt}-\mathrm{AL}$ are shifted to higher BEs, whereas the $\mathrm{O} 1 s$ peak of the $\mathrm{Cu}_{3} \mathrm{Pt}-\mathrm{AL}$ is shifted to a lower BE. From these results, the $\mathrm{Pt}$ species in the $\mathrm{Cu}_{3} \mathrm{Pt}-\mathrm{AL}$ believed to have been in the $\mathrm{PtO}_{x}$ state, and the $\mathrm{BE}$ values are in good agreement with literature values ( $\mathrm{Pt} 4 f_{5 / 2}: 77.4$ $74.5 \mathrm{eV}$, Pt $4 f_{7 / 2}$ : 74.1-71.2 eV; O $\left.1 s: 530.5-530.2 \mathrm{eV}\right) .{ }^{9-11)}$

The thermal characteristics of the $\mathrm{Cu}_{3} \mathrm{Pt}-\mathrm{AL}$ were subsequently investigated and Figs. 4(A) and 4(B) show the TG-DTA and the TPD profiles obtained for this material. The TG-DTA (Fig. 4(A)) indicates a change in mass with an onset at around $720 \mathrm{~K}$, accompanied by an endothermic process. Additionally, the TPD $(\mathrm{m} / \mathrm{e}=32)$ shows that $\mathrm{O}_{2}$ was desorbed under a He flow (Fig. 4(B)), in good agreement with the TG-DTA results. The proportional mass loss of the $\mathrm{Cu}_{3} \mathrm{Pt}-\mathrm{AL}$ (before and after the TG-DTA process) was ca. 0.854 , a value that indicates the decomposition of $\mathrm{PtO}_{2}$ to $\mathrm{Pt}\left(\mathrm{PtO}_{2} \rightarrow \mathrm{Pt}+\mathrm{O}_{2}(\mathrm{~g})\right)$ since the $\mathrm{Pt} / \mathrm{PtO}_{2}$ mass ratio is 0.859 .

The catalytic properties of the $\mathrm{Cu}_{3} \mathrm{Pt}-\mathrm{AL}$ were assessed using the oxidation of $\mathrm{CO}$ as a model reaction, and Fig. 5(A) summarizes the catalytic performance of both the $\mathrm{Cu}_{3} \mathrm{Pt}-\mathrm{AL}$
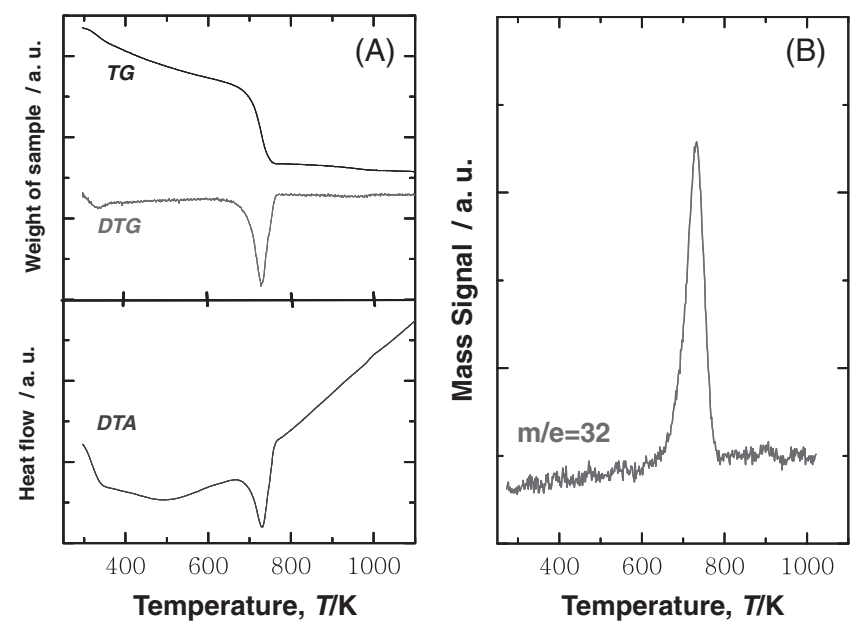

Fig. 4 (A) TG-DTA and (B) TPD profiles of a $\mathrm{Cu}_{3}$ Pt-AL sample.

and the Pt black during $\mathrm{CO}$ oxidation. In the case of the $\mathrm{Cu}_{3} \mathrm{Pt}-\mathrm{AL}$, the catalytic activity exhibited on cooling was significantly higher than the activity seen while increasing the temperature. As shown in Fig. 5(A), the hysteresis of the catalytic activity of the $\mathrm{Cu}_{3} \mathrm{Pt}-\mathrm{AL}$ sample contrasts with that observed for the Pt black catalyst. In general, the application of rising temperatures leads to sintering and a significant loss of catalytic activity in the case of unsupported metal catalysts, and the $\mathrm{Cu}_{3} \mathrm{Pt}-\mathrm{AL}$ applied in this study generated, clear diffraction peaks corresponding to fcc Pt following its use in the $\mathrm{CO}$ oxidation reaction (Fig. 1: $\mathrm{Cu}_{3} \mathrm{Pt}-\mathrm{AL}+\mathrm{AR}$ ). Sharpening of the Pt diffraction peaks was also observed for both the $\mathrm{Cu}_{3}$ Pt-AL and the Pt black (Fig. 1 and Fig. 5(B)) following the oxidation reaction, since the Pt particles readily undergo crystal grain growth as the temperatures applied during the reaction are increased up to $500 \mathrm{~K}$. Crystallite sizes of the $\mathrm{Cu}_{3} \mathrm{Pt}-\mathrm{AL}(\mathrm{AR})$ and the Pt black (AR), which are estimated from the XRD line broadening analysis using the Scherrer equation for the $\operatorname{Pt}(111)$ reflection, are estimated 

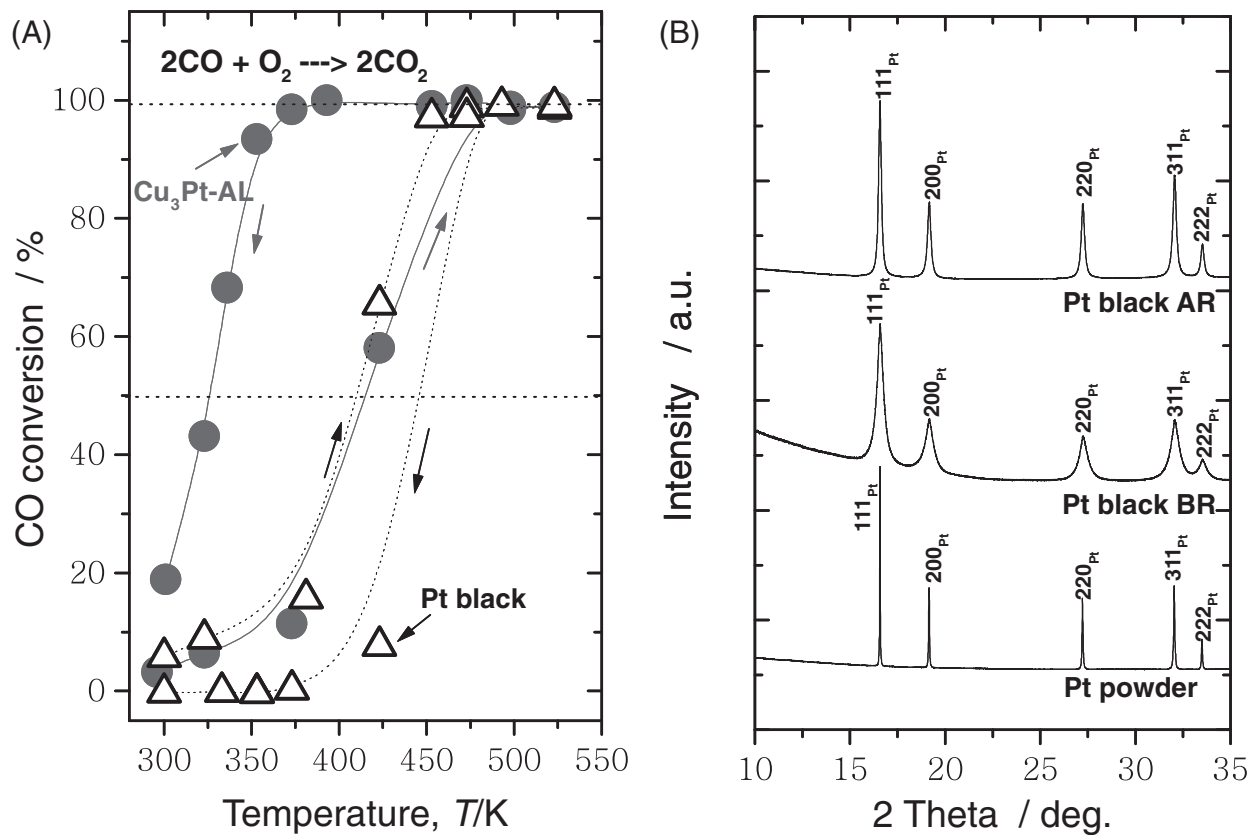

Fig. 5 (A) Catalytic activities of $\mathrm{Cu}_{3} \mathrm{Pt}-\mathrm{AL}$ and Pt black for $\mathrm{CO}$ conversion as a function of reaction temperatures and (B) SXRD patterns of Pt black before (BR) and after (AR) the CO oxidation reaction (SPring-8 BL15XU, $\lambda=0.065297 \mathrm{~nm}$ ).

11.9 and 20.0 (BR: 9.2) [nm], respectively. Interestingly, the decrease in the BET specific surface area of the $\mathrm{Cu}_{3} \mathrm{Pt}-\mathrm{AL}$ was much less than that of the Pt black catalyst (Table 1). Values of the areal rate $\left[\mu \mathrm{mol}_{\mathrm{CO}} \cdot \mathrm{min}^{-1} \cdot \mathrm{m}^{-2}\right.$-cat $]$ at $373 \mathrm{~K}$ (2nd run) of the $\mathrm{Cu}_{3} \mathrm{Pt}-\mathrm{AL}$ and the Pt black are 21.9 and 0.06 , respectively. Assuming all of surface Pt atoms play as active sites and $1.25 \times 10^{19} \mathrm{Pt}$ atoms per square meter $(20.8$ $\left[\mu \mathrm{mol}_{\mathrm{Pt}} \cdot \mathrm{m}^{-2}\right]$ ), apparent TOF values of the $\mathrm{Cu}_{3} \mathrm{Pt}-\mathrm{AL}$ and the Pt black can be estimated at $1.23 \times 10^{-3}$ and $2.19 \times 10^{-5}$ $\left[\mathrm{s}^{-1}\right]$, respectively. Interestingly, the TOF value of the $\mathrm{Cu}_{3} \mathrm{Pt}-$ $\mathrm{AL}$ is much larger than that of the Pt black. Therefore, it is suggested that am- $\mathrm{PtO}_{x}$ is very effective as a precursor of the unsupported Pt catalyst. Recently, Murao et al. investigated the structure of $\mathrm{Cu}_{3} \mathrm{Pt}-\mathrm{AL}$ using high-energy XRD coupled with anomalous X-ray scattering (AXS) and reported that the $\mathrm{Cu}_{3} \mathrm{Pt}-\mathrm{AL}$ was composed of a fine nanocomposite $\mathrm{Pt}(\mathrm{Cu})$ $\mathrm{Pt}(\mathrm{Cu}) \mathrm{O}_{x}{ }^{12)}$ When studying the preferential oxidation (PROX) of CO in hydrogen, Komatsu et al. found that the $\mathrm{Cu}$ atoms in a $\mathrm{PtCu}$ IMC plays an important role in supplying the oxygen necessary for the reaction to $\mathrm{CO}$ molecules adsorbed on neighboring Pt atoms. ${ }^{13)}$ Therefore, we cannot exclude the possibility that the presence of residual copper in the $\mathrm{Cu}_{3}$ Pt-AL may contribute to the catalytic properties of this material as well as to its thermal stability.

On the other hand, Adams's catalyst is a well-known platinum dioxides $\left(\mathrm{PtO}_{2} \cdot \mathrm{H}_{2} \mathrm{O}\right)$ material employed during organic syntheses involving hydrogenation and hydrogenolysis. ${ }^{14)}$ The oxide itself is not originally an active catalyst, but becomes active after exposure to hydrogen, whereupon it converts to platinum black, which is responsible for the catalytic activity. Adams's catalyst is typically prepared in molten sodium nitrate by the reaction of chloroplatinic acid $\mathrm{H}_{2} \mathrm{PtCl}_{6}$ or ammonium chloroplatinate $\left(\mathrm{NH}_{4}\right)_{2} \mathrm{PtCl}_{6}$ with sodium nitrate at high temperatures (583-973 K). ${ }^{14-16)}$ However, some sodium and chlorine are strongly retained in the final product, leading to deactivation and poisoning of the Pt catalyst. In order to mitigate this problem, therefore, it is necessary to devise improved method of preparing the catalyst, such as using $\mathrm{Cl}$-free reagents as precursors. In the present study, it was determined that the $\mathrm{Cu}_{3} \mathrm{Pt}$ alloy readily reacted with $\mathrm{HNO}_{3}$ to generate $\mathrm{PtO}_{x}$ even at $323 \mathrm{~K}$. Although a detailed mechanism by which amorphous $\mathrm{PtO}_{x}$ is formed during the leaching process is not presently known, it is nonetheless evident that amorphous $\mathrm{PtO}_{x}$ species were effectively formed under mild conditions when applying this technique. Consequently, the method described herein shows promise as a novel means of preparing such materials.

\section{Conclusions}

This study demonstrated that amorphous Pt oxides (am$\mathrm{PtO}_{x}$ ) are formed by the selective leaching of copper from a $\mathrm{Cu}_{3} \mathrm{Pt}$ alloy in concentrated $\mathrm{HNO}_{3}$ at $323 \mathrm{~K}$ for $12 \mathrm{~h}$. The resulting amorphous $\mathrm{Pt}$ oxides were characterized using SXRD, HXPS and thermal analysis. The catalytic performance of $\mathrm{am}-\mathrm{PtO}_{x}$ for the $\mathrm{CO}$ oxidation was found to be superior to that of a $\mathrm{Pt}$ black catalyst. Interestingly, the catalytic behavior of the $\mathrm{am}-\mathrm{PtO}_{x}$ exhibited a hysteresis different from that observed for the Pt black catalyst. This process represents a facile, non-thermal method for the preparation of amorphous $\mathrm{Pt}$ oxides that show promise as a novel, sodium and chlorine-free Adams's catalyst.

\section{Acknowledgements}

The authors are grateful to Dr. Reiko Murao and Prof. Dr. Kazumasa Sugiyama (IMR, Tohoku University) for helpful discussions. The authors would like to thank Dr. S. Ueda and Mr. Ishimaru for improving HXPS in BL15XU at SPring-8. Synchrotron analyses were performed with the approval of NIMS synchrotron X-ray station at SPring-8 facility, Japan (proposal nos. 2012A4500, 2012B4502, 2013A4900, 
2013A4902, 2013B4901 and 2013B4903). This work was supported in part by Grant-in-Aid for Scientific Research ((A) 23247117, (B) 24360329) from the Ministry of Education, Culture, Sports, Science and Technology (MEXT).

\section{REFERENCES}

1) M. Hakamada and M. Mabuchi: Crit. Rev. Solid State Mater. Sci. 38 (2013) 262-285.

2) V. Zielasek, B. Jürgens, C. Schulz, J. Biener, M. M. Biener, A. V. Hamza and M. Bäumer: Angew. Chem. Int. Ed. 45 (2006) 8241-8244.

3) C. Xu, J. Su, X. Xu, P. Liu, H. Zhao, F. Tian and Y. Ding: J. Am. Chem. Soc. 129 (2007) 42-43.

4) S. Kameoka and A. P. Tsai: Catal. Lett. 121 (2008) 337-341.

5) S. Kameoka and A. P. Tsai: J. Mater. Chem. 20 (2010) 7348-7351.
6) Y. Xu, H. Yoshikawa, J. H. Jang, M. Demura, K. Kobayashi, S. Ueda, Y. Yamashita, D. M. Wee and T. Hirano: J. Phys. Chem. C 114 (2010) 6047-6053.

7) M. Tanaka, Y. Katsuya and A. Yamamoto: Rev. Sci. Inst. 79 (2008) 075106.

8) K. S. W. Sing: Pure Appl. Chem. 54 (1982) 2201-2218.

9) M. Peuckert and H. P. Bonzel: Surf. Sci. 145 (1984) 239-259.

10) M.-C. Jung, H.-D. Kim, M. Han, W. Jo and D.-C. Kim: Jpn. J. Appl. Phys. 38 (1999) 4872-4875.

11) C. R. Parkinson, M. Walker and C. F. McConville: Surf. Sci. 545 (2003) 19-33.

12) R. Murao: Ph. D. Dissertation, (Tohoku University, 2012).

13) T. Komatsu, M. Takasaki, K. Ozawa, S. Furukawa and A. Muramatsu: J. Phys. Chem. C 117 (2013) 10483-10491.

14) V. Voorhees and R. Adams: J. Am. Chem. Soc. 44 (1922) 1397-1405.

15) R. Adams and R. L. Shriner: J. Am. Chem. Soc. 45 (1923) 2171-2179.

16) V. Ponec and G. C. Bond: Catalysis by Metals and Alloys, (Elsevier 1995) p. 319. 